\title{
A TUTELA DAS SITUAÇÕES JURÍDICAS EXISTENCIAIS PELO DIREITO NOTARIAL
}

\section{Manoel Antônio Silva Macêdo* Sarah Rêgo Goiatá*}

Resumo: $O$ presente artigo trata das possibilidades de promoção autonomia privada existencial pelo Direito Notarial, tendo como norte o seguinte problema: de que forma o Direito Notarial pode contribuir para a tutela das situações jurídicas existenciais, conferindo maior amplitude às possibilidades de exercício da autonomia privada pelo titular de direitos da personalidade? Por meio de pesquisa bibliográfica e documental, utilizando os métodos de abordagem dedutivo e indutivo, conjectura-se a hipótese de que os atos notariais podem instrumentalizar manifestações de vontade, em circunstâncias além das previstas, expressamente, no ordenamento jurídico, promovendo de maneira adequada o livre desenvolvimento da personalidade humana.

Palavras-chave: autonomia privada; diretivas antecipadas; doação de órgãos; reconstrução de vontade; situações jurídicas.

\section{THE PROTECTION OF EXISTENTIAL LEGAL SITUATIONS UNDER NOTARY LAW}

Abstract: This article deals with the possibilities of promoting existential private autonomy by Notary Law, having as its guide the following problem: how the Notarial Law can contribute to the protection of existential legal situations, giving greater scope to the possibilities of exercising private autonomy by the titleholder of personality rights? Through bibliographical and documental research, using the deductive and inductive approach methods, the hypothesis is conjectured that notarial acts can instrumentalize expressions of will, in circumstances beyond those expressly provided for in the legal system, adequately promoting the free development of human personality.

Keywords: private autonomy; advance directives; organ donation; reconstruction of will; legal situations.

\section{INTRODUÇÃO}

A pesquisa foi desenvolvida em torno do problema referente à necessidade de refletir com que abrangência o Direito Notarial pode promover o exercício da autonomia privada existencial, através da publicidade, autenticidade, segurança e eficácia dos atos notariais.

\footnotetext{
* Mestre e Doutorando em Direito Privado pela PUC Minas - Avenida 31 de março, nº 1020 - Prédio 93 - Dom Cabral - Belo Horizonte/MG - CEP: 30.535-000. E-mail: manoelantonio@msn.com.

* Mestranda em Direito Privado pela PUC Minas - Avenida 31 de março, no 1020 - Prédio 93 - Dom Cabral Belo Horizonte/MG - CEP: 30.535-000. Pós-graduanda em Patient Safety pela Johns Hopkins University Armstrong Institute for Patient Safety and Quality. Pesquisadora Científica de Biodireito. E-mail: sarahgoiata@gmail.com.
} 
Isso porque, a despeito da principiologia constitucional que tutela o livre desenvolvimento da pessoa humana, não raro a falta de um regramento legal para a definição do conteúdo, alcance e efeitos de atos de autonomia privada, no âmbito de situações jurídicas existenciais, acaba obstaculizando a plena autodeterminação do titular de direitos da personalidade.

Assim, identificadas tais premissas, a investigação volta-se para análise das possibilidades hermenêuticas na aplicação de regras e princípios do Direito Notarial, a fim de conferir condições de pleno exercício aos atos de autonomia privada quanto a aspectos da personalidade, que não se resumem meramente às questões de nome, estado e capacidade.

\section{BREVE INTRODUÇÃO HISTÓRICA AO DIREITO NOTARIAL}

Segundo Décio Antonio Erpen, é bem provável que a instituição da atividade notarial tenha antecedido à própria formação do Direito e do Estado, ante a necessidade de documentar certos fatos da vida, relações e negócios por pessoas que detinham a confiança dos seus pares, fazendo assim surgir a figura do notário (ERPEN, Décio Antonio, 1995 apud FERREIRA; RODRIGUES, 2018, p. 13).

Ferreira e Rodrigues (2018, p. 13) ensinam que há provas da existência do notário, desde as civilizações suméria (de 3.500 a 3.000 a.C.) e egípcia (de 3.200 a 325 a.C.).

No Egito Antigo, por exemplo, era o escriba quem lavrava os contratos privados, mediante o testemunho de três pessoas, para depois levá-los a um sacerdote, que os encerrava com um selo, a fim de impedir alterações posteriores (FERREIRA; RODRIGUES, 2018, p. 14).

Na Grécia, havia um técnico da memorização chamado mnemon, que ficava encarregado de formalizar e registrar os tratados, os atos públicos e os contratos privados (FERREIRA; RODRIGUES, 2018, p. 14).

Todavia, apenas no Império Romano, a pessoa incumbida de redigir e conservar os contratos adquiriu as feições do notário como se conhece hoje, muito em razão dos desafios de integrar os povos conquistados e documentar os negócios que se efetivavam, a fim de permitir a circulação controlada de pessoas e documentos (FERREIRA; RODRIGUES, 2018, p. 14). 
Apesar da imprecisão histórica quanto ao surgimento da fé pública notarial, Ferreira e Rodrigues (2018, p. 15) afirmam que ela decorre de uma prolongada construção pragmática, de usos e costumes do povo tendentes à adequada eficácia probatória de seus atos privados, que parece ter iniciado no reinado de Justiniano I, já que antes não há qualquer referência ao tabellios romano. Assim, é, provavelmente, no reinado de Justiniano I em que pode ser situado o nascimento do notariado atual.

Constata-se, pois, que os direitos notarial e registral se encontravam presentes, desde as primeiras sociedades humanas, em função da importância que sempre se deu ao registro de acontecimentos, bens e negócios, com caráter, eminentemente, patrimonial.

No Brasil, durante o período colonial, a regulamentação da atividade notarial era regida pelas ordenações vigentes em Portugal, que, mesmo após a independência do Brasil, continuaram sendo aplicadas, até a edição do Código Civil de 1916.

Tendo nascido meramente redatora, as necessidades sociais, especialmente após a Revolução Francesa, transformaram o notário em profissional dotado de fé pública, cuja função hoje vai muito além de receber a manifestação de vontade das partes, visto que passou a qualificá-la juridicamente, rechaçando eventuais ilicitudes, bem como se tornou responsável por dirigir, imparcialmente, os particulares na individualização regular de seus direitos e interesses (BRANDELLI, 2011).

Todavia, no ordenamento jurídico nacional, pode-se afirmar que a mudança de paradigma só ocorreu, de fato, com a Constituição Federal de 1988, mediante a adoção da cláusula geral de tutela e promoção da pessoa humana, que levou à funcionalização dos institutos de direito privado relacionados com o patrimônio aos interesses existenciais dos indivíduos.

Nesse cenário de incorporação de novos valores pela Constituição Federal de 1988, faz-se necessária a adoção de um conceito geral de categorias do agir humano, sobretudo em função da existência de centros de interesses sem titular, mas que, ainda assim, têm a proteção do Direito, a exemplo da doação em favor de nascituros, confirmando o reconhecimento de valores tutelados pelo Estado, quer tenham ou não expressão econômica.

A par disso, importa destacar a lição de Pietro Perlingieri, que define como situação jurídica o conceito geral de categorias de efeitos jurídicos atribuídos a alguns comportamentos humanos, a partir do qual são avaliados os efeitos do agir humano. Desse modo, mesmo centros de interesses destituídos de um sujeito destinatário são considerados situações 
jurídicas protegidas pelo Direito. Ainda consoante Perlingieri (2002, p. 105), os atos, que geram efeitos constitutivos, modificativos e extintivos, produzem situações jurídicas, tendo como exemplos o direito subjetivo, o poder jurídico (potestà), o interesse legítimo, a obrigação e o ônus.

\section{PRINCÍPIOS DO DIREITO NOTARIAL}

Os princípios são uma espécie de norma jurídica, do mesmo modo que as regras (leis), havendo distinção quanto ao modo de sua aplicação. Eles também se aplicam às situações de lacuna ${ }^{1}$, bem como orientam a interpretação das regras, prevalecendo sobre estas, em caso de conflito, o que os leva a serem considerados diretrizes do ordenamento.

Luiz Guilherme Loureiro (2017, p. 1022) entende que os princípios servem não apenas para auxiliar na interpretação e integração do ordenamento, como também para nortear a edição de novas leis.

Nos direitos notarial e registral, como em todos os outros ramos do direito, há princípios setoriais, ou seja, que se aplicam com especificidade ao objeto de estudo de determinado ramo.

Os princípios mais relevantes do direito notarial são: o princípio da fé pública, o princípio da legalidade, o princípio da formalidade, o princípio da justiça preventiva, o princípio da imparcialidade e independência, o princípio da rogação, o princípio da unicidade do ato notarial, o princípio da segurança jurídica e o princípio da conservação e publicidade.

O princípio da fé pública se refere ao poder de autenticar e certificar fatos e atos jurídicos, que passam a gozar de presunção de veracidade e certeza.

O princípio da legalidade impõe o dever ao notário de analisar a adequação de uma determinada conduta a normas e princípios do ordenamento jurídico, sob pena de invalidade.

O princípio da formalidade decorre da necessidade de obediência a determinadas formas ou solenidades, que a lei impõe como substância do ato.

O princípio da imparcialidade estabelece o dever de o notário tratar ambas as partes de forma equitativa, ainda que seus serviços tenham sido solicitados por uma delas.

\footnotetext{
${ }^{1}$ Reconhecendo a existência de princípios capazes de prover soluções para litígios, Ronald Dworkin nega a existência de lacuna, que, para os positivistas, autorizaria o juiz a agir com discricionariedade. (PEDRON; OMMATI, 2020, p. 70).
} 
O princípio da rogação reza que o notário não pode agir de ofício, visando à preservação de sua imparcialidade.

O princípio da unicidade do ato notarial significa que o ato notarial deve ser realizado em uma única oportunidade, sem interrupções, na presença das partes ou de seus representantes, impedindo que o ato seja alterado sob qualquer pretexto.

$\mathrm{O}$ princípio da segurança jurídica estabelece ao notário o dever de verificar a legalidade da forma e conteúdo dos documentos apresentados pelas partes, evitando o reconhecimento de elementos que causem insegurança ou incerteza.

O princípio da conservação e publicidade exige a ampla divulgação dos atos praticados pelo notário, que deve conservar os livros e documentos apresentados pelas partes em local seguro, garantindo o acesso a qualquer pessoa.

O princípio da justiça preventiva é observado pelo notário, quando este assegura às partes a conclusão de negócios jurídicos claros e equilibrados, prevenindo possíveis conflitos.

Assim, mesmo havendo regra explícita sobre determinada situação jurídica que os interessados queiram submeter à formalização jurídica ou à autenticação notarial, recorre-se sempre à aplicação dos princípios notariais, para garantia de existência, validade e eficácia dos atos praticados pelas partes, quer sejam eles de natureza patrimonial ou não.

\section{A PROMOÇÃO DA AUTONOMIA PRIVADA EXISTENCIAL PELO DIREITO NOTARIAL}

A seguir, serão analisadas as possibilidades da aplicação do Direito Notarial para assegurar o livre desenvolvimento da pessoa humana, por meio de atos notariais destinados a registrar atos e fatos jurídicos.

\subsection{A ata notarial e a escritura pública}

Segundo a classificação de João Teodoro da Silva (2002, p. 10), as atas notariais e as escrituras públicas estão entre os dois principais instrumentos públicos notariais. Pela escritura pública, em regra, são formalizados os atos jurídicos de cunho negocial, ao passo que a ata notarial se destina a documentar a ocorrência de fatos jurídicos humanos que não configuram negócios jurídicos. 
A despeito da clareza conceitual fornecida por João Teodoro da Silva, convém destacar outras distinções entre a ata notarial e a escritura pública, uma vez que a finalidade pretendida pode exigir a lavratura de um ou outro instrumento público.

Brandelli (2011) conceitua a ata notarial como o instrumento público, mediante o qual o notário capta, por seus sentidos, uma determinada situação ou fato, que ocorreu em sua presença, e o translada para seus livros de notas ou para outro documento, conforme art. $6^{\circ}$, III, da Lei n. ${ }^{\circ} 8.935 / 94$.

A ata notarial não pode, portanto, ter por conteúdo um negócio jurídico, uma vez que este remete à lavratura de escritura pública.

Desse modo, Leonardo Brandelli (2011) afirma que o objeto da ata notarial é obtido por exclusão, tendo por diferença básica a existência, ou não, de declaração de vontade, que está presente na escritura, e ausente na ata.

Pedroso e Lamanauskas (2015, p. 281) ensinam que na ata notarial há somente a narração de um fato, que não deve conter qualquer tipo de juízo valorativo.

Segundo Brandelli (2011), o notário narra na ata notarial apenas o acontecido, seja ele lícito ou ilícito, e não a própria declaração de vontade humana, uma vez que para este caso, por exigência legal, o instrumento adequado é a escritura pública.

Dessa forma, na elaboração da ata notarial há mera atividade autenticante do notário, enquanto, na confecção da escritura pública, o notário atua como assessor imparcial das partes, que buscam criar, modificar ou extinguir direitos (BRANDELLI, 2011).

Assim, diferentemente da escritura pública, a ata notarial não tem eficácia substantiva nem executiva, mas apenas o condão de pré-constituir prova suscetível de ponderação pelo juiz (BRANDELLI, 2011).

A ata exerce, pois, a importante função de também declarar as informações e fatos disponíveis para todos, inclusive os dados representados por imagem ou som gravados em arquivos eletrônicos, conforme estabelece o parágrafo único ${ }^{2}$ do art. 384 do Código de Processo Civil (CPC) (TEIXEIRA, 2018, p. 187).

João Teodoro da Silva (2002, p. 19) cita os seguintes exemplos de atas notariais: atas de presença, referência, protocolização, depósito, requerimento, notificação, notoriedade etc.

\footnotetext{
${ }^{2}$ Art. 384. A existência e o modo de existir de algum fato podem ser atestados ou documentados, a requerimento do interessado, mediante ata lavrada por tabelião.

Parágrafo único. Dados representados por imagem ou som gravados em arquivos eletrônicos poderão constar da ata notarial.
} 
Por sua vez, a escritura se destina a formalizar ato jurídico de cunho negocial, abrangente de contratos, convenções e declarações unilaterais de vontade (SILVA, 2002, p. 21).

Tarcisio Teixeira (2018, p. 187) afirma que a escritura pública contém a manifestação de vontade das partes interessadas, reproduzindo apenas aquilo que elas informam ao notário, sem investigar se todo o suporte fático é verdadeiro.

Outrossim, a escritura pública também se distingue das atas notariais, porque, na primeira, a assinatura das partes corresponde à outorga ou consentimento ao texto redigido, enquanto nas atas o mesmo não ocorre, podendo o tabelião lavrá-la, ainda que o interessado se recuse a assiná-la depois, pois não se está realizando nenhum ato ou negócio jurídico. Também não é necessário ao notário realizar um juízo de capacidade do requerente da ata notarial, bastando que ele tenha capacidade legal, e que o notário verifique a existência de interesse legítimo (BRANDELLI, 2011).

No que tange ao arquivamento dos atos, as escrituras são protocolares, ao passo que as atas podem ser protocolares ou extraprotocolares (BRANDELLI, 2011).

Logo, ficam evidentes as diferenças entre a ata notarial e a escritura pública, sendo cada uma útil à sua maneira para a tutela das situações jurídicas existenciais.

\subsection{A escritura pública e as Diretivas Antecipadas de Vontade}

A palavra autonomia ${ }^{3}$ é conferida dentro da medicina e do Biodireito para descrever o poder do paciente de tomar decisões sobre sua saúde, atuando como sujeito ativo, titular do direito de escolha e de sua biografia.

A importância da valoração deste princípio biojurídico também está no fato de colocar limitações à interferência do Estado sobre o direito de autodeterminação do sujeito, apresentando, portanto, um aspecto negativo.

É importante ressaltar que para que a vontade privada seja, efetivamente, determinante de efeitos jurídicos, deve haver autonomia reconhecida ao indivíduo, não apenas

\footnotetext{
${ }^{3}$ Com a passagem do Estado Liberal para o Estado Social, a autonomia da vontade, que conferia ampla liberdade de atuação do sujeito na satisfação de seus interesses, perdeu espaço para a autonomia privada, enquanto poder reconhecido à pessoa pelo Estado de determinar, dentro de certos limites, os efeitos jurídicos de seus comportamentos livremente assumidos.
} 
no âmbito patrimonial da sua esfera jurídica, mas também no aspecto pessoal (NORONHA, 2003, p. 390-391).

E no sentido de garantir respeito e promoção à autonomia do indivíduo, observa-se a apresentação do conceito basilar de consentimento informado pelo Código de Nuremberg, que o cita entre um de seus dez princípios.

1. O consentimento voluntário do ser humano é absolutamente essencial. Isso significa que a pessoa envolvida deve ser legalmente capacitada para dar o seu consentimento; tal pessoa deve exercer o seu direito livre de escolha, sem intervenção de qualquer desses elementos: força, fraude, mentira, coação, astúcia ou outra forma de restrição ou coerção posterior; e deve ter conhecimento e compreensão suficientes do assunto em questão para tomar sua decisão [...]. (CÓDIGO DE NUREMBERG, 1947).

Assim, com a preocupação de possibilitar a autonomia do paciente com eficácia futura, no âmbito de cuidados à sua saúde, foram criadas as diretivas antecipadas de vontade, para o momento em que ainda existe o discernimento acerca das consequências das decisões que serão tomadas, já que para sua existência exige-se a vontade livre, esclarecida e lícita.

A origem das diretivas antecipadas é atribuída ao direito estadunidense, através do The Patient Self-Determination Act (PSDA), em vigor nos Estados Unidos, desde 01/11/1991. O PSDA é assim considerado o primeiro texto normativo, que se tem conhecimento, a respaldar a autonomia prospectiva do paciente para estabelecer, por si só ou através de um representante nomeado, as intervenções médicas às quais aceita se submeter.

Nesse sentido, as diretivas antecipadas de vontade surgiram como reflexo da atual relação médico-paciente, na qual se assegura a possibilidade de exercício da autonomia privada pelo enfermo de registrar suas opções e objeções a tratamentos, em caso de eventual incapacidade futura.

No Brasil, a Resolução do Conselho Federal de Medicina (CFM) n. ${ }^{\circ}$ 1995/2012 define as diretivas antecipadas de vontade como a manifestação prévia e expressa sobre cuidados e tratamentos médicos que o paciente quer, ou não, receber no momento de eventual situação de incapacidade, podendo também haver a designação de um representante para tal fim.

Logo, as diretivas antecipadas de vontade buscam, em essência, resguardar os direitos concernentes à autonomia existencial do paciente, no âmbito de cuidados médicos, 
com eficácia em situações futuras, quando faltar àquele a capacidade de fato para a tomada de decisões.

As diretivas antecipadas de vontade são, portanto, um instrumento deontológico, que viabiliza o exercício da autonomia privada existencial do paciente, prevalecendo sobre os desejos dos familiares ou qualquer outro parecer não médico. Têm natureza jurídica de negócio unilateral, gratuito, personalíssimo e revogável a qualquer tempo. Sujeitam-se aos requisitos de existência e validade de qualquer negócio jurídico, não havendo necessidade de testemunhas ou registro em cartório de notas.

No plano da eficácia, as diretivas antecipadas dependem do implemento da condição suspensiva relativa à incapacidade superveniente da pessoa que as fez, e sua validade depende da observância de preceitos éticos da medicina, além dos requisitos previstos em lei para os negócios jurídicos.

Não há leis no ordenamento jurídico brasileiro que disponham sobre diretivas antecipadas, de forma que são previstas apenas na Resolução CFM n. ${ }^{\circ}$ 1.995/2012.

Sá e Naves (2018, p. 107) descrevem abaixo as três formas usadas para formalizar as diretivas antecipadas:

a) Living will: o paciente define, enquanto ainda capaz, quais tratamentos médicos quer ou não receber, quando não puder mais expressar sua vontade;

b) Durable power of attorney for health care (mandato duradouro): trata-se de negócio jurídico bilateral por meio do qual o paciente nomeia terceiro de sua confiança para decidir acerca de quais tratamentos médicos receberá, quando não puder mais manifestar, pessoalmente, seu consentimento livre e esclarecido;

c) Advanced core medical directives: é um misto de living will e durable power of attorney for health care, ocorrendo quando o paciente estabelece quais tratamentos de saúde aceita ou não receber, e também nomeia alguém para decidir qual deles será realizado.

Em regra, as diretivas antecipadas observam o princípio da liberdade das formas, mas recomenda-se que sejam registradas em escritura pública, na presença do notário, considerando a vantagem de haver a presunção de que foram feitas de livre e espontânea vontade, sem coação ou constrangimento.

A despeito da liberdade que se confere ao paciente para renunciar, previamente, a tratamentos e intervenções médicas, há certos limites sobre os quais não se permite avançar, 
como a prática da eutanásia ativa direta ou indireta ${ }^{4}$, conforme prevê o art. $41^{5}$ da Resolução

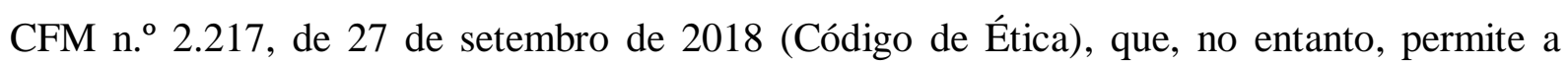
suspensão ou não iniciação de ações diagnósticas ou terapêuticas inúteis (ortotanásia).

Em âmbito familiar, as diretivas incidirão como lenitivo, uma vez que evitarão os conflitos e o sofrimento decorrentes da tomada de decisão, tendo em vista a vontade expressa do paciente, gerando efeitos para todos.

Além disso, com as diretivas assegura-se o respeito às convicções do paciente nos assuntos relacionados, não apenas à qualidade de vida, mas também às decisões de caráter existencial, a exemplo da outorga para doação de órgãos, indo ao encontro do disposto no art. 1.857, § 2. ${ }^{\circ}$, do Código Civil, segundo o qual são válidas as disposições testamentárias de caráter não patrimonial, ainda que o testador somente a elas se tenha limitado.

Por isso, entende-se também legítimo o uso das diretivas antecipadas para materializar a decisão quanto à doação de órgãos e tecidos, além das disposições do paciente acerca de tratamentos médicos, já que o ordenamento jurídico e as normas deontológicas não restringem tal possibilidade.

A instrumentalização das diretivas em escritura pública também teria a vantagem de afastar a necessidade de confirmação ${ }^{6}$ suplementar post mortem da vontade do doador por seus parentes, quando já houvesse a nomeação de alguém da confiança do disponente comprometido em cumprir a sua vontade.

Assim, para que haja uma maior segurança jurídica, recomenda-se que o documento das diretivas antecipadas seja levado a registro em escritura pública, conferindo-se, portanto, eficácia erga omnes; prevenindo conflitos entre familiares e responsáveis legais; bem como assegurando a autonomia privada existencial do paciente, inclusive com eficácia post mortem.

\subsection{Ata notarial como prova em processo judicial}

\footnotetext{
${ }^{4}$ Sá e Naves afirmam que, na forma ativa, a eutanásia pode ser direta (intenção) e indireta (efeito): a primeira diz respeito à intenção do agir médico voltada para abreviar a vida do paciente terminal e em estado de sofrimento, enquanto a segunda diz respeito ao efeito produzido pela ação médica de aliviar a dor e os sintomas, que acaba produzindo o evento morte. (SÁ; NAVES, 2018, p. 372).

5 Art. 41. Abreviar a vida do paciente, ainda que a pedido deste ou de seu representante legal.

${ }^{6}$ Art. $4^{\circ}$ A retirada de tecidos, órgãos e partes do corpo de pessoas falecidas para transplantes ou outra finalidade terapêutica, dependerá da autorização do cônjuge ou parente, maior de idade, obedecida a linha sucessória, reta ou colateral, até o segundo grau inclusive, firmada em documento subscrito por duas testemunhas presentes à verificação da morte.
} 
As alternativas oferecidas pelo Direito Notarial para o exercício de atos de autonomia privada existencial não se restringem apenas ao uso de escrituras públicas, visto que a complexidade da vida, em uma sociedade plural, não se satisfaz com uma única solução.

Além disso, já há algum tempo as implicações da anomia em questões referentes à relação médico-paciente se apresentam no desenvolvimento das práticas e posições dos tribunais.

E mesmo nas situações de conflitos éticos tratadas por dispositivos deontológicos são encontradas lacunas, que podem comprometer o pleno exercício da autonomia privada existencial, considerando que a Resolução CFM n. ${ }^{\circ}$ 1.995/2012 somente preserva a autonomia do paciente que fez diretivas antecipadas.

De forma ilustrativa, cita-se um caso julgado pelo Tribunal de Justiça do Rio Grande do Sul (2011), em que se discutiu se deveria ser considerada a vontade supostamente transmitida por uma paciente ao seu filho, antes de perder a capacidade, para que não fosse submetida a hemodiálise, diante do sofrimento maior que tal procedimento poderia causar.

No julgado em análise, a paciente estava acometida de séria doença e incapaz de expressar sua vontade aos médicos. O conflito, que dizia respeito à realização ou não do tratamento médico, foi protagonizado entre filho e neto da paciente, os quais divergiam sobre a manutenção dos tratamentos médicos. O Hospital ajuizou ação cautelar de suprimento de vontade em face de ambos, objetivando que fosse declarado o responsável por autorizar os médicos a proceder com o tratamento indispensável.

O Relator ponderou que o processo refletia a disputa entre a ortotanásia e a distanásia, bem como entendeu pela resolução do impasse, atribuindo a condição de responsável legal ao descendente mais próximo, no caso o filho, a quem, alegadamente, teria sido transmitida a vontade da paciente.

Ementa: CONSTITUCIONAL. MANTENÇA ARTIFICIAL DE VIDA. DIGNIDADE DA PESSOA HUMANA. PACIENTE, ATUALMENTE, SEM CONDIÇÕES DE MANIFESTAR SUA VONTADE. RESPEITO AO DESEJO ANTES MANIFESTADO. Há de se dar valor ao enunciado constitucional da dignidade humana, que, aliás, sobrepõe-se, até, aos textos normativos, seja qual for sua hierarquia. O desejo de ter a "morte no seu tempo certo", evitados sofrimentos inúteis, não pode ser ignorado, notadamente em face de meros interesses econômicos atrelados a eventual responsabilidade indenizatória. No caso dos autos, a vontade da paciente em não se submeter à hemodiálise, de resultados altamente duvidosos, afora o sofrimento que impõe, traduzida na declaração do filho, há de ser respeitada, notadamente quando a ela se contrapõe a já referida preocupação 
patrimonial da entidade hospitalar que, assim se colocando, não dispõe nem de legitimação, muito menos de interesse de agir. (RIO GRANDE DO SUL, 2011).

Vê-se, portanto, que a falta de critérios jurídicos para subsidiar a reconstrução judicial da vontade leva alguns julgadores a lançar mão da ordem legal estabelecida para a função de curador do incapaz, como no julgado supra em que a manifestação dada pelo filho foi prevaleceu, em detrimento da discordância do neto.

Contrário a esse entendimento, Sá e Naves (2018, p. 386) argumentam que observar uma ordem de preferência, em virtude da impossibilidade de manifestação do paciente, impede a construção hermenêutica do caso concreto.

No acórdão foi também citado o caso da americana Terri Schiavo, que ficou em estado vegetativo por 15 anos, em razão de uma lesão em seu córtex cerebral causada por uma parada cardíaca. Depois de muitos anos cuidando de Terri, seu marido Michael Schiavo enfrentou uma disputa nos tribunais contra seus sogros acerca da realização de eutanásia. Após 14 apelações e petições legais, o caso de Terri foi federalizado, devido à grande repercussão nacional e internacional, chegando à Suprema Corte, que manteve a decisão judicial de primeira instância, determinando a retirada dos tubos de hidratação e alimentação de Terri.

Tendo em vista casos como os citados acima, o desafio posto é reconhecer a autonomia privada de pacientes para manifestar, em caso de doenças terminais e irreversíveis, a escolha por cuidados paliativos, que não pode ficar limitada à condição de deixar diretivas antecipadas, sabido que elas não comportam forma prescrita, e quando o enfermo tenha manifestado sua vontade de forma clara e consciente perante terceiros.

No entanto, prevalecem as ressalvas quanto ao caso de pessoas que tatuam no peito a frase do not resuscitate (DNR), expressando uma vontade contrária ao emprego de técnicas de ressuscitação. Esse fenômeno gera um dilema ético para os médicos de emergência e cuidados intensivos, que cuidam do paciente apresentado ao pronto-socorro inconsciente e em estado crítico. Sem a orientação de parentes próximos ou de diretivas antecipadas, parece improvável que a equipe médica decida observar o que diz a tatuagem $D N R$.

Disso decorre a importância do direito notarial para a tutela das situações jurídicas existenciais, a fim de que as manifestações de vontade de pacientes recebam forma legal, instrumentalizando com autenticidade, validade e eficácia um ato ou negócio jurídico existencial. 
Nesse tocante, entende-se que o art. 384 do CPC constitui um importante avanço para a tutela das situações jurídicas, ao estabelecer que a "existência e o modo de existir de algum fato podem ser atestados ou documentados, a requerimento do interessado, mediante ata lavrada por tabelião".

Em primeira leitura, percebe-se que não houve qualquer limitação quanto à natureza do fato a ser atestado ou documentado, no sentido de que pode ser ele patrimonial ou existencial.

Assim, considerando que a esfera existencial toca direitos de personalidade, alguns deles alçados à condição de direitos fundamentais, coloca-se a seguinte questão: a ata notarial pode ser utilizada como meio de prova, para possibilitar o exercício de situações jurídicas existenciais da pessoa considerada incapaz?

Inobstante o avanço da jurisprudência, ainda é longo o caminho a percorrer até a ampliação do uso da ata notarial para tratar de questões existenciais, ainda assim compreendese que há plena possibilidade do uso da ata notarial para atestar preferências e vontades quanto a tratamentos e cuidados médicos que o indivíduo desejaria ou não receber, em situação de incapacidade, caso tivesse deixado diretivas antecipadas.

Considerando, ainda, que, nos dias atuais, qualquer pessoa pode ser usuária de contas em redes sociais, onde registra, abertamente, suas vontades e preferências, inclusive sobre temas como cuidados médicos que estaria disposto ou não a receber, numa situação de incapacidade, e não raro compartilha tais informações com familiares e amigos, torna-se possível conhecer detalhes da intimidade e da vida privada do indivíduo. Todavia, apesar da tendência de constante exposição em redes sociais, também é frequente que essa mesma pessoa não se precavenha, no sentido deixar registradas suas diretivas antecipadas.

Nesse ambiente virtual, as pessoas constroem uma biografia, às vezes atrelada a uma linha de tempo, levando a crer ser possível o uso da ata notarial como meio de prova, a fim de propiciar a reconstrução da vontade do paciente terminal, quanto à suspensão ou não iniciação de tratamentos médicos, ou recebimento de cuidados paliativos.

No entanto, ainda que se entenda pela aplicação da ortotanásia ou de cuidados paliativos, será necessário comprovar a ineficácia terapêutica, até porque a recusa quanto aos que oferecem possibilidade de cura, com risco de vida, só pode ser feita de forma expressa e consciente, conforme prevê o art. 15 do Código Civil. 
Ademais, a exigência de que o tratamento médico seja comprovadamente ineficaz importa para assegurar os interesses do paciente relativamente incapaz, na fase terminal de doenças graves e incuráveis, já que, na ausência de diretivas antecipadas, somente quando não houver eficácia da ação terapêutica pode-se falar em benefício ${ }^{7}$, na aplicação da ortotanásia ou dos cuidados paliativos, em conformidade com a Resolução CFM n. ${ }^{\circ}$ 1.805/2006.

Com relação aos cuidados paliativos, o próprio CFM autoriza, por meio da Resolução n. ${ }^{\circ}$ 1.805/2006, a suspensão de procedimentos médicos na fase terminal de enfermidades graves e incuráveis, bem como estabelece o dever médico de esclarecer ao doente e ao seu representante legal as alternativas terapêuticas disponíveis, como os cuidados paliativos.

Conforme ensinam Teixeira e Sá (2018, p. 248), compreende-se a ideia de cuidados paliativos como um tratamento integral que confere maior qualidade de vida à pessoa e para aqueles que compartilham do seu sofrimento, ainda que em outra dimensão, mesmo que isso implique em viver menos.

Logo, a ideia de assegurar ao indivíduo diversas formas de exercício da autonomia privada, através da prática de atos notariais, se coaduna com o princípio do livre desenvolvimento da personalidade, que para atingir a máxima eficácia, não prescinde da garantia da tutela das escolhas existenciais indispensáveis à realização da dignidade humana.

\section{CONSIDERAÇÕES FINAIS}

Entende-se que tanto a ata notarial quanto a escritura pública são instrumentos públicos do Direito Notarial de grande importância para o livre desenvolvimento da personalidade humana em situações jurídicas existenciais.

$\mathrm{Na}$ ausência superveniente da capacidade, a instrumentalização das diretivas antecipadas por escritura pública permite que se dê publicidade à vontade da pessoa acerca de cuidados médicos, com eficácia erga omnes, prevenindo conflitos familiares.

Para casos em que não há mais a possibilidade manifestação expressa quanto aos tratamentos que a pessoa quer ou não receber, a reconstrução da vontade, mediante a lavratura de ata notarial, constitui uma alternativa viável para assegurar a autonomia privada existencial

\footnotetext{
${ }^{7} \mathrm{O}$ benefício aqui mencionado corresponde à observância do princípio bioético da beneficência, que impõe ao profissional da saúde o dever de direcionar esforços apenas para fazer bem ao paciente.
} 
de pacientes em suas questões de saúde, especialmente em situações de conflitos, podendo servir como meio de prova para os casos judicializados.

Diante do exposto, verifica-se que a incidência das regras e princípios do Direito Notarial contribui sobremaneira para o pleno exercício dos atos de autonomia privada existencial quanto a aspectos da personalidade humana.

\section{REFERÊNCIAS}

BRANDELLI, Leonardo. Teoria geral do direito notarial. - 4. ed. - São Paulo : Saraiva, 2011. E-book.

CÓDIGO DE NUREMBERG (1947). In: WIKIPEDIA: the free encyclopedia. [San Francisco, CA: Wikimedia Foundation, 2010]. Disponível em:

https://pt.wikipedia.org/wiki/Código_de_Nuremberg. Acesso em: 5 abr. 2021.

CONSELHO FEDERAL DE MEDICINA (Brasil). Resolução CFM n. ${ }^{\circ} 2.217$, de 27 de setembro de 2018, modificada pelas Resoluções CFM no 2.222/2018 e 2.226/2019. Código de Ética Médica. Disponível em: https://portal.cfm.org.br/images/PDF/cem2019.pdf. Acesso em: 5 abr. 2021.

CONSELHO FEDERAL DE MEDICINA (Brasil). Resolução CFM n. ${ }^{\circ}$ 1.995/2012. Dispõe sobre as diretivas antecipadas de vontade dos pacientes. Disponível em: http://www.portalmedico.org.br/resolucoes/cfm/2012/1995 2012.pdf. Acesso em: 5 abr. 2021.

FERREIRA, Paulo Roberto Gaiger; RODRIGUES, Felipe Leonardo. Tabelionato de notas : Vol. 1 - teoria geral do direito notarial e minutas. - 2. ed. - São Paulo : Saraiva Educação, 2018 .

LOUREIRO, Luiz Guilherme. Registros públicos: teoria e prática. - 8. ed. rev., atual e ampl. - Salvador: Editora Juspodivm, 2017. 
NORONHA, Fernando. Direito das obrigações: fundamentos do direito das obrigações, introdução à responsabilidade civil. São Paulo: Saraiva, 2003.

PEDRON, Flávio Quinaud; OMMATI, José Emílio. Teoria do direito contemporânea: uma análise das teorias jurídicas de Robert Alexy, Ronald Dworkin, Jürgen Habermas, Klaus Günther e Robert Brandom. 2 ed. rev. e ampl. - Belo Horizonte: Conhecimento Editora, 2020.

PEDROSO, Regina; LAMANAUSKAS, Milton Fernando. Direito notarial e registral atual. - 2. ed. - Rio de Janeiro : Forense; São Paulo: MÉTODO, 2015.

PERLINGIERI, Pietro. Perfis do direito civil. Tradução de: Maria Cristina De Cicco. 3. ed., rev., e ampl. - Rio de Janeiro: Renovar, 2002.

RIO GRANDE DO SUL. Tribunal de Justiça do Rio Grande do Sul (21 a Câmara Cível). Apelação Cível n. ${ }^{\circ}$ 70020868162. Processo n. ${ }^{\circ}$ 70042509562. Relator: Des. Armínio José Abreu Lima da Rosa. Julgado em: 1 jun. 2011. Disponível em: http://www1.tjrs.jus.br/site php/consulta/consulta processo.php?nome comarca=Tribunal\%2 $\underline{0 \mathrm{de} \% 20 \mathrm{Justiça} \% 20 \mathrm{do} \% 20 \mathrm{RS} \& v e r s a 0=\& \text { versao_fonetica }=1 \& \text { tipo }=1 \& \mathrm{id} \_ \text {comarca }=700 \& \text { num }}$ _processo_mask $=\&$ num_processo $=70042509562 \&$ codEmenta $=7706337 \&$ temIntTeor=tru. Acesso em: 5 abr. 2021.

SÁ, Maria de Fátima Freire de; NAVES, Bruno Torquato de Oliveira. Bioética e biodireito. 4. ed. Belo Horizonte: Del Rey, 2018.

SILVA, da João Teodoro. Tabelião do $6 .^{\circ}$ Ofício de Notas de Belo Horizonte. Adaptação da obra “Ata Notarial”. Boletim Cartorário. Edição 1 - Ano 2002.

TEIXEIRA, Ana Carolina Brochado; SÁ, Maria de Fátima Freire de. Cuidados Paliativos: entre autonomia e solidariedade. Revista novos Estudos Jurídicos - Eletrônica, Vol. 23, n. ${ }^{\circ}$ 1, jan-abr 2018. Disponível em: https://siaiap32.univali.br/seer/index.php/nej/article/view/13037. Acesso em: 5 abr. 2021. 
TEIXEIRA, Tarcisio. Curso de direito e processo eletrônico: doutrina, jurisprudência e prática. - 4. ed. atual. e ampl. - São Paulo : Saraiva Educação, 2018.

TERRI SCHIAVO. In: WIKIPÉDIA: a enciclopédia livre. [San Francisco, CA: Wikimedia Foundation, 2017]. Disponível em: https://pt.wikipedia.org/wiki/Terri_Schiavo. Acesso em: 5 abr. 2021. 